\title{
Prevalence and Etiologies of Obstructive Renal Failure in the Nephrology Department of the University Hospital Center of Point G, Bamako, Mali
}

\author{
Seydou Sy, ${ }^{12}$, Magara Samaké2,3, Moctar Coulibaly4, Moussa Salifou Diallo2,5, Atabième Kodio', \\ Hamadoun Yattara ${ }^{1,2}$, Abdoul Aziz Mahamane Seribah Coulibaly ${ }^{1}$, Aboubacar Sidiki Fofana ${ }^{1}$, \\ Djénèba Diallo1, Sah Dit Baba Coulibaly¹, Modi Sidibé1, Moustapha Tangara',2, Alkaya Touré1, \\ Saharé Fongoro1,2
}

\author{
${ }^{1}$ Nephrology and Haemodialysis Department of the University Hospital Center (UHC) of Point G, Bamako, Mali \\ ${ }^{2}$ Faculty of Medicine and Odontostomatology of Bamako, Bamako, Mali \\ ${ }^{3}$ Nephrology Unit of the Fousseyni Daou Hospital in Kayes, Kayes, Mali \\ ${ }^{4}$ Nephrology Unit of the Mali Gavardo Hospital of Sébénikoro, Bamako, Mali \\ ${ }^{5}$ Urology Department of University Hospital Center of Kati, Kati, Mali \\ Email: *seydousy2002@yahoo.fr
}

How to cite this paper: Sy, S., Samaké, M., Coulibaly, M., Diallo, M.S., Kodio, A., Yattara, H., Coulibaly, A.A.M.S., Fofana, A.S., Diallo, D., Coulibaly, S.D.B., Sidibé, M., Tangara, M., Touré, A. and Fongoro, S. (2020) Prevalence and Etiologies of Obstructive Renal Failure in the Nephrology Department of the University Hospital Center of Point G, Bamako, Mali. Open Journal of Nephrology, 10, 187-198.

https://doi.org/10.4236/ojneph.2020.103018

Received: April 2, 2020

Accepted: July 4, 2020

Published: July 7, 2020

Copyright $\odot 2020$ by author(s) and Scientific Research Publishing Inc. This work is licensed under the Creative Commons Attribution International License (CC BY 4.0).

http://creativecommons.org/licenses/by/4.0/

(c) (i) Open Access

\section{Abstract}

Introduction: Obstructive renal failure (ORF) or obstructive uropathy is defined by the simultaneous presence of impaired renal function and urinary excretory tract dilatation on medical imaging. It accounts for $2 \%$ to $10 \%$ of the causes of acute renal failure (ARF). Objective: To determine the prevalence and etiologies of ORF in the nephrology department of the University Hospital Center of Point G. Methodology: This was a descriptive study with retrospective data collection conducted from January 1, 2017 to June 30, 2018. All patients hospitalized with renal failure due to urinary tract obstruction were included. The parameters studied were age, gender, etiology, type of renal impairment, procedures performed, surgical outcomes of the procedure, pre-and post-management creatinine levels. Information on these clinical and paraclinical variables was collected from individual hospitalization and patient follow-up records. Results: Among 1133 patients, 83 had obstructive renal failure, a prevalence of $7.32 \%$. The sex ratio was 1.86 . The mean age was $48.99 \pm 6.81$ years with extremes of 7 and 102 years. Signs suggestive of lower urinary tract obstruction were, in order of frequency: dysuria $(50.6 \%)$, urinary burns $(44.6 \%)$, urinary frequency $(44.6 \%)$, pollakiuria $(44.6 \%)$, macroscopic hematuria $(25.3 \%)$, low back pain $(21.6 \%)$, total anuria (18.1\%). The etiologies were dominated by lithiasis 36 cases $(43.4 \%)$, tumours 
32 cases (38.55\%) followed by sequelae of bilharziasis 12 cases (14.50\%). Conclusion: Obstructive renal failure is becoming more and more common. The etiology is essentially of lithiasic and tumor origin. It must be treated early to allow total or partial recovery of renal function.

\section{Keywords}

Prevalence, Etiologies, Obstructive Renal Failure, Mali

\section{Introduction}

Obstructive renal failure is defined as acute or chronic obstruction of the urinary tract, occurring bilaterally or in a single anatomical or functional kidney. This type of renal failure is called post-renal, because its etiology is downstream of the kidneys. It accounts for $2 \%$ to $10 \%$ of the causes of ARF. [1]. Early removal of the obstacle conditions its reversibility [1]. Their severity lies in the reduced capacity of the kidneys to ensure their sodium excretion functions leading to the risk of hydrosodium overload on the one hand and acute pulmonary oedema on the other hand with the risk of threatening hyperkalaemia. Their diagnostic and therapeutic management has been improved by advances in imaging and endo-urology. However, this form of renal failure continues to pose many problems in facilities with limited technical facilities, more so than in developing countries [2].

The aim of this work was to determine the prevalence and etiologies of obstructive renal failure in the nephrology department of the UHC of Point G.

\section{Patients and Methods}

This was a descriptive retrospective data collection study of patients managed for obstructive kidney disease in the Nephrology Department of Point G University Hospital from January 1, 2017 to June 30, 2018 (16 months). Patients were included in this study without distinction of sex, age or nationality, hospitalized for renal failure whose cause is an obstacle in the urinary tract and having a medical record including clinical variables, paraclinical variables, procedures performed, surgical results, creatinine levels before and after drainage.

Clinical variables sought included dysuria, anuria, acute urine retention, bladder globe, low back pain, macroscopic hematuria. Abdominal pelvic ultrasound, uroscanner or abdominal-pelvic CT scan looked for hydronephrosis, uretero-hydronephrosis or causes of obstruction such as lithiasis, tumours of the bladder or prostate, sequelae of bilharzia or extra-renal tumours, among others. Information on these clinical and paraclinical variables was collected from individual hospitalization and patient follow-up records.

\section{Definition Criteria Used}

Chronic kidney disease (CKD) is defined as the chronic ( $>3$ months) and ir- 
reversible decrease in glomerular filtration rate $(\mathrm{GFR})<60 \mathrm{ml} / \mathrm{min} / 1.73 \mathrm{~m}^{2}$ [3]. Chronicity was selected in front of:

- A history of previous pathologic creatinine or the existence of hematuria and/or proteinuria for at least 3 months;

- On ultrasound, small kidneys $(<10 \mathrm{~cm})$, poorly differentiated;

- An aregenerative normocytic normocytic anemia;

- Hypocalcemia associated with hyperphosphatemia.

> Definition of acute renal failure (Table 1):

The obstructive nature of renal failure was retained by the presence of an obstacle in the urinary tract either on clinical examination (anuria, bladder goblet, urine retention, dysuria, lumbar pain, macroscopic hematuria, urinary frequency or burns) or on medical imaging (hydronephrosis or ureterohydronephrosis, lithiasis, tumour) and/or improvement in renal function after removal of the obstacle.

The evolution was considered favourable if there was an improvement in renal function.

Strict adherence to the anonymity of each patient's medical record was observed.

Data entry and analysis were carried out with the SPSS 20 software (French version). The statistical test used was the Pearson Chi2 with a significant value $\mathrm{P}$ $<0.05$.

\section{Results}

During the study period, 1133 patients were admitted for renal failure, including 83 cases of obstructive renal failure, i.e. a prevalence of $7.32 \%$. The sample was composed of 29 women (34.9\%) and 54 men (65.1\%), i.e. a sex ratio of 1.86 . The mean age was $48.99 \pm 6.81$ years with extremes of 7 and 102 years. Patients aged 40 years and over accounted for $71.1 \%$ of cases. The age range 40 - 60 years accounted for $47 \%$ of cases. The uro-nephrological history suggestive of lower urinary tract obstruction was in order of frequency: dysuria (50.6\%), urinary burns (44.6\%), pollakiuria (44.6\%), macroscopic hematuria (25.3\%), renal colic

Table 1. KDIGO (Kidney Disease Improving Global Outcome 2012) universal definition of acute renal failure [4].

\begin{tabular}{|c|c|c|}
\hline IRA Stadium & Creatinine & Diuresis \\
\hline 1 & $\begin{array}{c}\text { Increase }>26 \mu \mathrm{mol} / \mathrm{L}(3 \mathrm{mg} / \mathrm{L}) \text { in } 48 \text { hours } \\
\text { or }>50 \% \text { in } 7 \text { days }\end{array}$ & $<0.5 \mathrm{ml} / \mathrm{kg} / \mathrm{h}$ for 6 to $12 \mathrm{hrs}$. \\
\hline 2 & Creatinine $\times 2$ & $<0.5 \mathrm{ml} / \mathrm{kg} / \mathrm{h}$ for $\geq 12 \mathrm{hrs}$. \\
\hline 3 & $\begin{array}{c}\text { Creatinine } \times 3 \\
\text { or } \\
\text { creatinine }>354 \mu \mathrm{mol} / \mathrm{L}(40 \mathrm{mg} / \mathrm{L}) \\
\text { in the absence of prior value } \\
\text { or } \\
\text { need for dialysis }\end{array}$ & $\begin{array}{c}<0.3 \mathrm{ml} / \mathrm{kg} / \mathrm{h} \text { for } \geq 24 \mathrm{hrs} . \\
\text { or } \\
\text { anuria } \geq 12 \mathrm{~h}\end{array}$ \\
\hline
\end{tabular}

${ }^{\star}$ We used the creatinine criterion in this study. 
(9.6\%), anuria $(9.6 \%)$ and acute urinary retention $(8.4 \%)$. The reason for hospitalization was hypercreatininemia (97.6\%) associated with dysuria (49.4\%), macroscopic hematuria (25.3\%), low back pain (21.6\%), total anuria (18.1\%). The functional and physical signs related to the uremic syndrome were asthenia (81.9\%), vomiting (74.4\%), anorexia (66.3\%) and hypertension (49.5\%) (Cf. Figure 1 and Figure 2). At the paraclinical level, ultrasonography of the urinary tree in all our patients showed hydronephrosis and ureterohydronephrosis in $61.5 \%$ and $38.5 \%$ of cases respectively (Cf. Table 2, Figure 3 ). The abdominal-pelvic CT scan performed in 42 patients showed bilateral ureterohydronephrosis in 50\% of cases (Cf. Table 3, Figures 4-6). Table 4 summarizes the different causes found on abdominal-pelvic ultrasonography. Ureteral ureteral lithiasis and bilharzian sequelae were the most frequently found on CT with $23.53 \%$ each (Cf. Table 5).

The etiologies were dominated by lithiasis 36 cases i.e. 43.4\% (ureteral: 29 cases $(34.93 \%)$, bladder: 7 cases $(8.4 \%)$ ), tumours 32 cases i.e. $38.55 \%(\mathrm{BPH}: 18$ cases $(21.8 \%)$, adenocarcinoma of the prostate: 6 cas $(7.22 \%)$, bladder tumour: 3 cas $(3.60 \%)$, cervical tumour: 3 cas $(3.60 \%)$, kidney tumour: 2 cas $(4.80 \%)$ followed by sequelae of bilharziasis 12 cas $(14.50 \%)$.

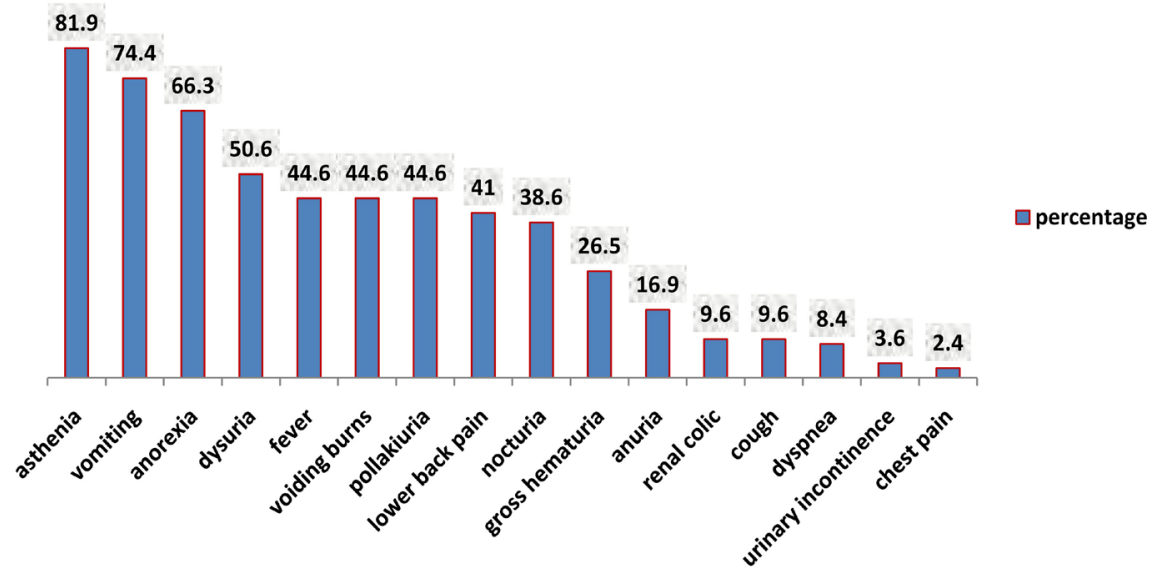

Figure 1. Distribution according to functional signs.

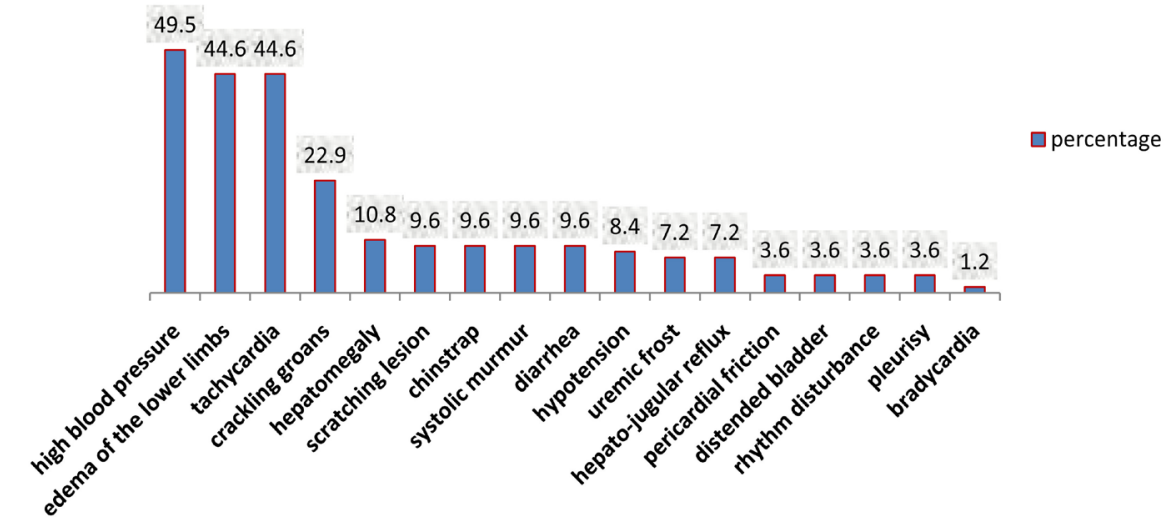

Figure 2. Distribution according to physical signs. 


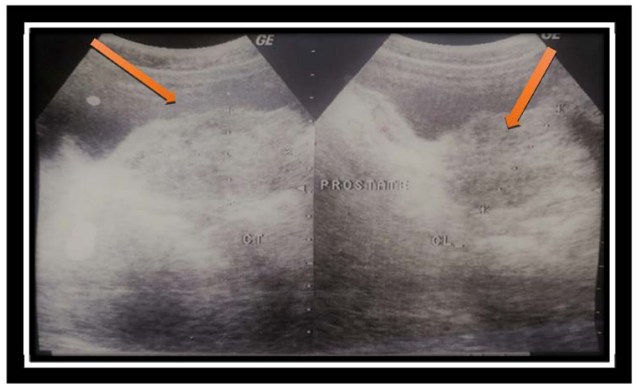

(a)

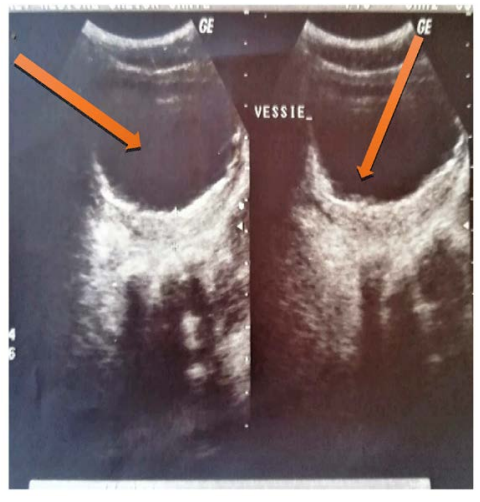

(b)

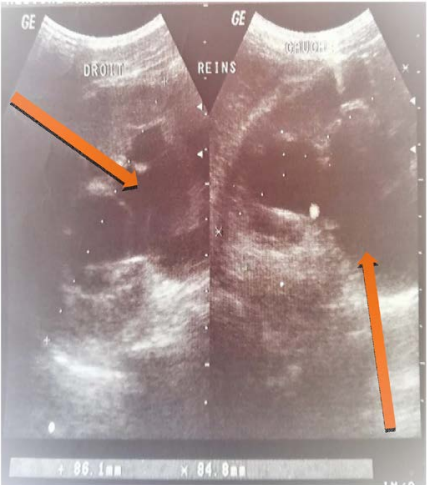

(c)

Figure 3. Abdomino-pelvic ultrasound: homogeneous hypertrophy of the prostate (a) associated with localized thickening of the bladder wall in favor of bilharzia cystitis (b) with impact on the upper urinary tract (bilateral uretero-hydronephrosis) (c). (arrows).

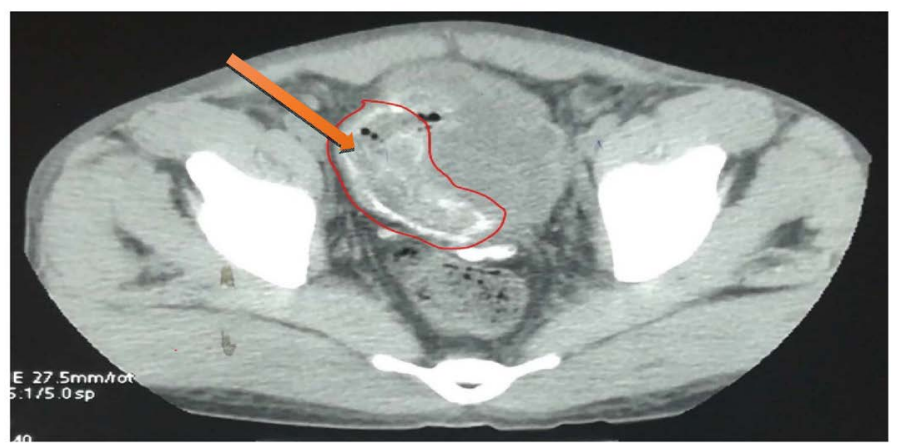

Figure 4. Abdominal CT scan of right lateral pseudotumour thickening of the bladder with calcification areas (arrow).

Table 2. Distribution of patients by urinary tract ultrasound result $(n=83)$.

\begin{tabular}{ccc}
\hline Ultrasound & Staff & Percentage \\
\hline Hydronephrosis & 51 & 61.5 \\
Bilateral & 45 & 54.2 \\
Unilateral & 6 & 7.3 \\
Ureterohydronephrosis & 32 & 38.5 \\
Bilateral & 30 & 36.1 \\
Unilateral & 2 & 2.4 \\
\hline
\end{tabular}



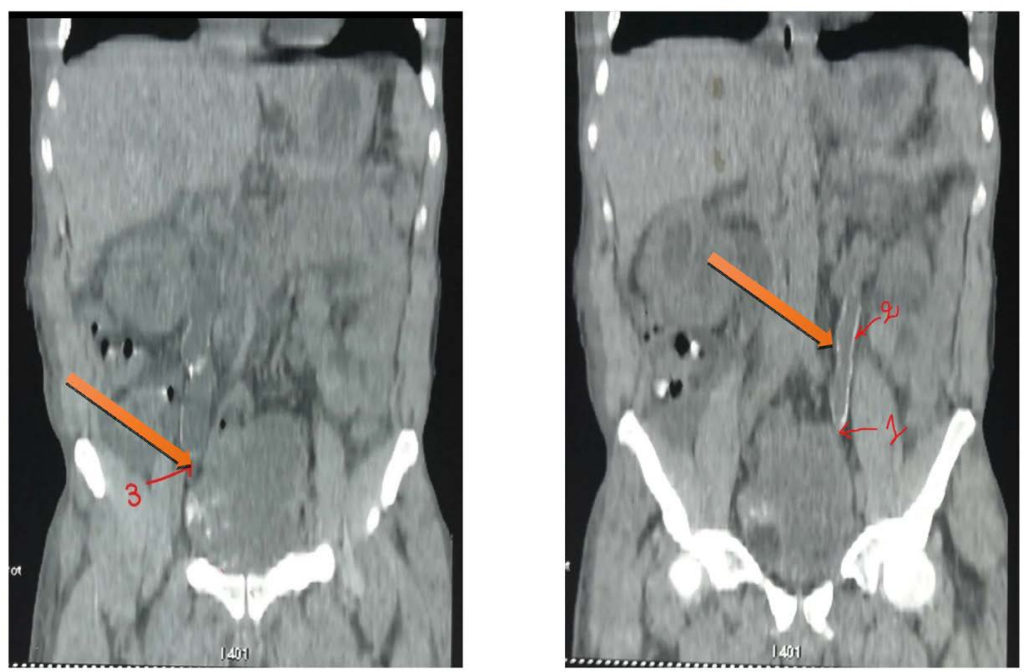

Figure 5. Abdominal CT scan suggestive of bilateral ureterohydronephrosis with calcifications of the ureteral walls (2) and stenosis of the uretero bladder junction bilaterally (1, 3) (arrow)

Table 3. Distribution of patients by CT scan result $(n=42)$.

\begin{tabular}{ccc}
\hline Computed tomography & Staff & Percentage \\
\hline Bilateral ureterohydronephrosis & 21 & 50 \\
Hydronephrosis & 17 & 40.5 \\
Bilateral & 15 & 35 \\
Unilateral & 2 & 4.8 \\
Normal & 4 & 9.5 \\
\hline
\end{tabular}

Table 4. Distribution of patients by etiology of obstruction on abdominopelvic ultrasound $(\mathrm{N}=83)$.

\begin{tabular}{|c|c|c|c|}
\hline \multicolumn{2}{|c|}{ Abdominopelvic ultrasound } & \multirow{2}{*}{$\begin{array}{c}\text { Staff } \\
36\end{array}$} & \multirow{2}{*}{$\begin{array}{c}\text { Percentage } \\
43.37\end{array}$} \\
\hline Intra-luminal & & & \\
\hline & Ureteral lithiasis & 29 & 34.93 \\
\hline & Bladder lithiasis & 7 & 8.4 \\
\hline \multirow[t]{5}{*}{ Intra-parietal } & & 21 & 25.30 \\
\hline & Bladder tumor & 3 & 3.60 \\
\hline & Kidney tumor & 2 & 2.40 \\
\hline & Ureteral stricture & 4 & 4.80 \\
\hline & Bilharzia sequelae & 12 & 14.50 \\
\hline \multirow[t]{5}{*}{ Extrinsic } & & 30 & 36.14 \\
\hline & Benign prostatic hypertrophy & 18 & 21.68 \\
\hline & Prostatic adenocarcinoma & 6 & 7.22 \\
\hline & Retroperitoneal fibrosis & 3 & 3.62 \\
\hline & Cervical tumor & 3 & 3.62 \\
\hline
\end{tabular}




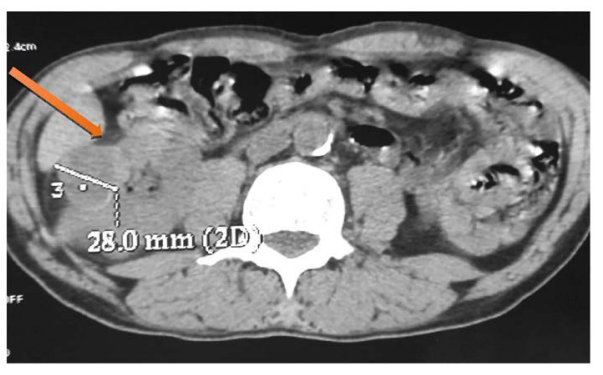

Figure 6. Abdominal CT scan: expansive process at the expense of the right renal cortex measuring $28 \mathrm{~mm}$ long axis (arrow).

Table 5. Distribution of patients by etiology of CT obstruction $(n=51)$.

\begin{tabular}{|c|c|c|c|}
\hline \multicolumn{2}{|c|}{ Abdominopelvic ultrasound } & \multirow{2}{*}{$\begin{array}{c}\text { Staff } \\
20\end{array}$} & \multirow{2}{*}{$\begin{array}{c}\text { Percentage } \\
39.21\end{array}$} \\
\hline Intra-luminal & & & \\
\hline & Ureteral lithiasis & 12 & 23.53 \\
\hline & Calici lithiasis & 3 & 5.88 \\
\hline & Bladder Lithiasis & 2 & 3.92 \\
\hline & Urethral stricture & 2 & 3.92 \\
\hline \multirow[t]{5}{*}{ Intra-parietal } & & 18 & 35.29 \\
\hline & sequelae of bilharziasis & 12 & 23.53 \\
\hline & Bladder tumor & 3 & 5.8 \\
\hline & Grawitz tumor & 2 & 3.92 \\
\hline & Neurological bladder & 1 & 1.96 \\
\hline \multirow[t]{6}{*}{ Extrinsic } & & 13 & 25.49 \\
\hline & Benign prostatic hypertrophy & 5 & 9.81 \\
\hline & Cervical Tumour & 3 & 5.88 \\
\hline & Retroperitoneal fibrosis & 2 & 3.92 \\
\hline & Prostatic adenocarcinoma & 2 & 3.92 \\
\hline & Rectal tumor & 1 & 1.96 \\
\hline
\end{tabular}

Renal failure was acute and chronic in 17 cases (20.5\%) and 45 cases (54.2\%), respectively. The nature of the renal impairment was not specified in $25.3 \%$ of cases. The mean value of creatinine was $1284.087 \mu \mathrm{mol} / \mathrm{l}$ with extremes of 506 and $2063 \mu \mathrm{mol} / \mathrm{l}$. The mean creatinine level increased from $1284.087 \mu \mathrm{mol} / \mathrm{l}$ at entry to $579.605 \mu \mathrm{mol} / \mathrm{l}$ at exit. Urinary tract infection was present in $59.7 \%$ of cases and the isolated germ was Escherichia Coli in 32.8\% of cases. Proteinuria was less than $1 \mathrm{~g} / 24$ hours in $55.17 \%$, more than $1 \mathrm{~g}$ in $24.1 \%$, while it was nil in $20.7 \%$ of cases.

Anemia was found in $92.40 \%$ of patients and was normocytic normochrome (54.43), microcytic hypochrome (6.33\%) and normocytic hypochrome (3.79\%).

Metabolic abnormalities were observed: dysnatremia (hyponatremia $=48.6 \%$ and hypernatremia $=10 \%$, dyskalemia (hyperkalemia $=55.7 \%$, hypokalemia $=$ 
4.3\%). Hypocalcemia and hyperphosphatemia were present in $68.6 \%$ and $82.5 \%$ of patients respectively.

In our study, the surgical intervention consisted of cytolithotomy (31.6\%), ureterolithotomy $(21 \%)$, adenectomy $(15.8 \%)$, uretero-vesical reimplantation (15.8\%), pyelolithotomy (10.5\%) (Cf. Figure 7). Antibiotic therapy was associated with surgical treatment in $72.3 \%$ of cases. Twenty-one point seven percent $(21.7 \%)$ of patients were dialysis. The average length of hospital stay was 14.29 days.

The evolution was favourable in 59.04\% (complete recovery in 17 cases (20.48\%), partial recovery of renal function in 12 cases $(14.46 \%)$ and 20 cases of transfer to other services $(24.10 \%))$. There were 30 cases $(36.14 \%)$ of death and 4 patients lost to follow-up (4.82\%).

\section{Discussion}

The ORF, once an uncommon or rather underestimated situation in the institution, has become relatively common nowadays. The prevalence of urinary obstruction is difficult to establish. This prevalence was $7.32 \%$ in our study. In Ouagadougou in 2011 and in Benin in 2017, obstructive kidney disease accounted for $17 \%$ and $34 \%$ of cases respectively [2] [5]. The male predominance was clear (65.1\% vs $34.9 \%)$. Many authors have also reported this male predominance [5]. The average age is 49 years and $47 \%$ of the patients are between 40 and 60 years of age. Bennan. S in 1995, Ndoye in 2015 reported an average age of 48 years and 57.92 years respectively [6] [7]. In Benin, fifty-two percent (52\%) were older than 50 years [5]. The mean observed creatinine level was 1284 $\mu \mathrm{mol} / \mathrm{l}$ with extremes of $506 \mu \mathrm{mol} / \mathrm{l}$ and $2063 \mu \mathrm{mol} / \mathrm{l}$ at admission. Lower mean creatinine levels than ours were observed in Benin and Ivory Coast, $152 \mu \mathrm{mol} / \mathrm{l}$ and $548 \mu \mathrm{mol} / 1$ respectively [5] [8]. Renal failure was acute and chronic in 17 cases $(20.5 \%)$ and 45 cases $(54.2 \%)$ respectively. In $25.3 \%$ of the cases the trait was not specified. Hamadi found in a series of 62 patients treated for renal obstruction a $21 \%$ prevalence of chronic renal failure [9]. Acute obstructive renal

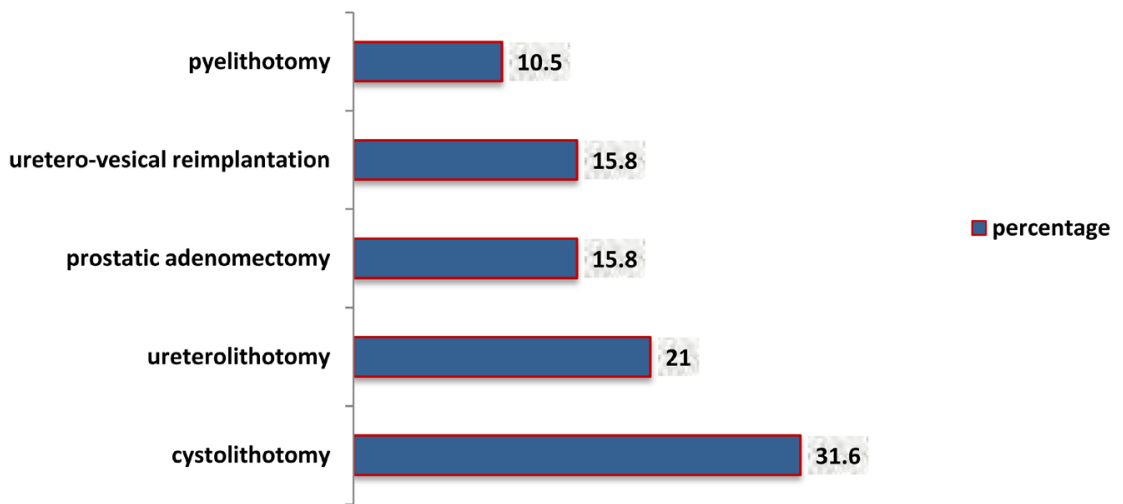

Figure 7 . Breakdown by type of urological procedure. ${ }^{*}$ Ureterolithotomy $=$ uretero-vesical reimplantation + nephrolithotomy + double JJ probe placement. Others: JJ probe $(n=2)$, striping $(n=1)$, fistulography $(n=1)$, cervicoprostatic recess $(n=2)$. 
failure is symptomatic and mainly manifests itself as pain [1]. In the majority of our patients, the clinical picture was dominated by signs suggestive of a uremic syndrome, namely asthenia (81.9\%), vomiting (74.4\%) and anorexia (66.3\%). Signs suggestive of lower urinary tract obstruction were, in order of frequency: dysuria $(50.6 \%)$, urinary burns $(44.6 \%)$, urinary frequency $(44.6 \%)$, pollakiuria (44.6\%), macroscopic hematuria (25.3\%), low back pain (21.6\%), total anuria (18.1\%). Similar proportions were reported in Ouagadougou and Cotonou [2] [10]. Mondet F et al. reported a prevalence of symptoms favouring upper urinary tract obstruction such as low back pain and renal colic at 25\% [11]. In the case of bilateral obstruction, the symptomatology is that of obstructive anuria. In addition to acute bilateral pain, anuria is also present [12] [13]. Delayed diagnosis leads to hydroelectrolytic disorders that worsen the clinical picture and worsen the patient's vital prognosis in the absence of urgent and appropriate management [14]. Major metabolic disorders found were hyperkalemia (55.7\%), hyponatremia $(48.6 \%)$, hypernatremia (10\%) and hypokalemia $(4.3 \%)$. The frequency of phosphocalcic disorders (hyperphosphatemia $82.5 \%$ ) and hypocalcaemia $(68.6 \%)$ is explained by the high rate of chronic renal failure in our study, i.e. $54.2 \%$. Severe hyponatremia is most often the result of water overload with a risk of pulmonary oedema [2].

Renal ultrasonography, carried out as an emergency procedure, revealed dilatation of the upper excretory tract and sometimes the etiology. Dilatation of the upper excretory tract was observed in all our patients (100\%). A dilatation rate of $74.5 \%$ and $92 \%$ was reported in Benin in 2015 and 2017 respectively [5] [10]. Although ultrasound is still the first-line examination in developing countries, it is increasingly being surpassed by CT, which in addition to dilatation allows visualization of the cause and study of renal parenchyma. In our study, the CT scan performed in 42 patients showed dilatation of the excretory tract in $90 \%$ of cases. Govani et al. reported $54 \%$ excretory tract dilatation diagnosed on first-line CT in their series [15].

The etiologies were dominated by lithiasis 36 cases or $43.4 \%$ (ureteral:29 cases (34.93\%), bladder: 7 cases (8.4\%)), tumours 32 cases or $38.55 \%$ (BPH:18 cases (21.8\%), adenocarcinoma of the prostate: 6 cases (7.22\%), bladder tumor: 3 cases (3.60\%), cervical tumor: 3 cases (3.60\%), kidney tumor: 2 cases $(4.80 \%)$ followed by sequelae of bilharziasis 12 cases (14.50\%) on ultrasound. The frequency of ureteral lithiasis, bilharzian calcifications, and benign hypertrophy was $28.6 \%$, $28.6 \%$, and $11.9 \%$ of cases on CT scan, respectively. In the literature upper urinary tract obstruction is dominated by lithiasis [12] [13] [14]. In a series of 247 cases of metastatic prostate cancer, Konan et al. reported $34.2 \%$ of the cases of renal failure [16]. In our study, there were $4.8 \%$ of prostate cancer cases. Indeed, some cases of benign prostatic hyperplasia $(\mathrm{BPH})$ with hydronephrosis are not always accompanied by obstructive renal failure, while other cases of BPH without ureterohydronephrosis are complicated by renal failure [17].

Although there are recommendations from learned societies regarding the 
management of renal failure in general, none to our knowledge provide specific recommendations to guide clinical decision making in the specific case of obstructive AKI [1].

Despite this lack of recommendations, our patients received antibiotic therapy (72.3\%), water intake $(51.8 \%)$, urinary catheterization $(38.6 \%)$, percutaneous nephrostomy (34.9\%), antihypertensive treatment (32.5\%), blood transfusion (32.50\%) and urological surgery (22.9\%). Twenty-two percent (22\%) of patients received dialysis. In the presence of ARF, the KDIGOs recommend initiating emergency extrarenal dialysis when hydroelectrolytic complications or overload are life-threatening in the short term [4]. A double J ureteral endoprosthesis, a percutaneous nephrostomy catheter or the Detour system for extra-anastomotic internal urinary diversion should be used for a high barrier [18] [19]. The time to reversibility of the lesions is difficult to specify. Recovery would not be related to the extent of dilatation [20].

$\mathrm{Wu}$ believes that kidney function impaired by an obstruction never normalizes after surgical removal. The procedure relieves pain, prevents further deterioration and infection [21].

Limitations of the study: patients whose records were incomplete or even unusable due to lack of financial means to carry out radiological and biological explorations, return home against medical advice, non-consent of some but also the early occurrence of death during the study, contributed to significantly reduce the size of our sample.

\section{Conclusion}

Obstructive renal failure is becoming increasingly common. The etiology is essentially of lithiasis and tumour origin. It must be treated early to allow total or partial recovery of renal function.

\section{Conflicts of Interest}

The authors declare that they have no conflict of interest in relation to this article.

\section{References}

[1] Guerrot, D. and Tamion, T. (2013) Obstructive Renal Failure from the Resuscitator's Point of View. CME Progress, 23, 19-22. https://doi.org/10.1016/j.fpurol.2012.10.001

[2] Zango, B., Kaboré, F.A. and Da, S. (2011) Epidemiological Aspects and Diagnosis of Obstructive Renal Failure at CHU Yalgado Ouedragode Ouagadougou. Revue CAMES, 12, 109-112.

[3] Hulot, J.-S. (2017) Chronic Renal Failure and Chronic Renal Diseases in Collège universitaire des enseignants de néphrologie. 7th Edition, Edition Ellipses, Paris.

[4] Acute Kidney Injury Work Group (2012) Kidney Disease: Improving Global Outcomes (KDIGO). KDIGI Clinical Practice Guideline for Acute Kidney Injury. Kidney International Supplements, 2, 1-138. 
[5] Hello, A.S., Gandaho, K.I.E., Hodonou, A.M., et al. (2017) Obstructive Renal Failure at the Tanguiëta Zone Hospital in Benin: Epidemiological and Diagnostic Aspects. Uro-Andro, 1, 335-340.

[6] Bennani, S., Bebbagh, A., Jonal, A., El Mrin, M. and Benjellovn, S. (1995) Obstructive Anuria: About 30 Cases. Annales d Urologie, 29, 159-162.

[7] Ndoye, M., Niang, L., Natchagandé, M., Jalloh, M., Labou, I. and Gueye, S.M. (2014) Nephrectomies: Indications, Techniques and Results in the Urology Department of the Hôpital General Grand Yoff of Dakar. Uro-andro, 1, 120-128.

[8] Coulibaly, N., Dje, K., Yao, H., Boka, M.D., Kouakou, A., Akassimattou, N., Bagni, L.P. and Sangaré, T.S. (2016) Upper Urinary Tract Obstruction: Diagnostic Circumstance and Method of Drainage. Uro Andro, 1, 2336.

[9] Hamadi, A., Hajage, D., Van Glabeke, E., Belenfaut, X., Vincent, F., Gonzalez, F., et al. (2012) Severe Post Renal Acute Kidney Injury, Post-Obstructive Diuresis and Renal Recovery. BJU International, 110, E1027-E1034. https://doi.org/10.1111/j.1464-410X.2012.11193.x

[10] Natchagandé, G., Avakondjo, J.D.G., Haounnasso, P.P., et al. (2015) Obstructive Renal Failure: Epidemiological Aspect and Diagnosis in 51 Cases at the $\mathrm{CHU}$ de Cotonou. Black African Medicine, 62, 16-22.

[11] Mondet, F., Chartier Kastler, E., Yonneau, L., et al. (2002) Epidemiology of Urological Emergencies at the University Hospital Centre. Progrès en Urologie, 12, 437-442.

[12] Muthukrishna, P.R., Chandrasingh, J.B., Grace, J.R., et al. (2016) Predictor of Renal Recovery in Renal Failure Secondary to Bilateral Obstructive Urolithiasis. Arab Journal of Urology, 14, 269-274. https://doi.org/10.1016/j.aju.2016.08.001

[13] Sameh, K., Mohammed, S.E., Hany, A.M., et al. (2013) Renal Recoverability in Infants with Obstructive Calcular Anuria: Is It Better than in Older Children? Journal of Pediatric Urology, 9, 1178-1182. https://doi.org/10.1016/j.jpurol.2013.05.003

[14] Hamadi, A. and Das, V. (2015) Acute Obstructive Renal Failure in Adults in Intensive Care: Management and Prognostic Factor. Resuscitation, 24, 661-667.

[15] Giovani, S.M., Fabio, C.V., Manoj, M., et al. (2016) Irreversible Renal Function Imparment Due to Silent Ureteral Stones. Urology, 93, 33-39. https://doi.org/10.1016/j.urology.2016.02.042

[16] Konan, P.G., Gowee, E.E., Dekou, A.H., et al. (2015) Metastatic Prostate Cancer in the Urology Department of the Cocody UHC. Uro Andro, 1, 172-176.

[17] Andrew, D.R., Michael, M.L. and Steven, J.J. (2005) Is Benign Prostatic Hyperplasia a Risk Factor for Chronic Renal Failure? The Journal of Urology, 173, 691-696. https://doi.org/10.1097/01.ju.0000153518.11501.d2

[18] Herody, M. (2008) Management of Obstructive Removal Syndrome (ORS) after Urologic Treatment of Obstructive Anuria. Advances in CME Urology, 18, F25-F28. https://doi.org/10.1016/S1761-676X(08)70015-4

[19] Petriconi, R. and Zores, T. (2014) Dérivation du haut appareil urinaire par sonde urétérale, double J, néphrostomie ou pontage interne: Principes, techniques et complications. EMC Tech Chir Urol, 7, 41-140.

[20] The Norman. L; Buzelin, J.M., Bouchot, O., Rigand, J. and Karam, G. (2005) Upper Urinary Tract Physiology, Pathophysiology of Obstructions and Function Assessment. Annals of Urology, 39, 30-48. https://doi.org/10.1016/j.anuro.2005.01.002 
[21] Wu, A.K., Tran, T.C., Sorensen, M.D., Durack, J.C. and Stoller, M.L. (2012) Relative Renal Function Does Not Improve after Relieving Chronic Renal Obstruction. BJU International, 109, 1540-1544. https://doi.org/10.1111/j.1464-410X.2011.10788.x 